\title{
Container Ship Investment Analysis Using Picture Fuzzy Present Worth Analysis
}

\author{
๑i Eda Boltürk \\ İstanbul Technical University, Department of Industrial Engineering, İstanbul, Turkey
}

\begin{abstract}
Investment analysis plays an important role in today's global engineering projects. The present worth analysis is an important investment analysis tool and method in engineering economics. These analyses are performed by humans, and human thoughts are hesitant. Fuzzy sets are frequently used in the literature to eliminate ambiguities in human thoughts. In 1965, Zadeh proposed fuzzy logic as a method of obtaining improved solutions to problems. Since then, fuzzy logic has extended to include hesitant fuzzy sets, q-rung fuzzy sets, Pythagorean fuzzy sets, picture fuzzy sets, type-2 fuzzy sets, Fermatean fuzzy sets, and Spherical fuzzy sets. As can be seen in the literature, present worth analysis has also been extended to its fuzzy versions, such as hesitant present worth analysis and spherical fuzzy present worth analysis. In this study, picture fuzzy present worth analysis is proposed as a new extension of present worth analysis that uses picture fuzzy sets in to create an alternative usage in investment analysis. The introduced method is presented step by step, and a sensitivity analysis is presented with risky parameters in the present worth analysis. Furthermore, the proposed method is compared with spherical fuzzy and classic crisp present worth analysis. The proposed method is used in container ship investment analysis, and future suggestions are provided in the conclusion section.
\end{abstract}

\section{Keywords}

Engineering economics, Picture fuzzy sets, Container ship, Maritime logistics, Investment analysis

\section{Introduction}

Currently, container ship management is a significant issue because of the increase in trade volume owing to globalization. Through information technology, box cargo transportation has revolutionized the maritime trade industry. The oceans and seas are home to about 50,000 merchant ships registered in 150 countries, carrying approximately $90 \%$ of global trade, which encompasses all types of cargo [1]. In 2007, 15 billion tons of cargo were transported by sea to 20,000 ports. For example, Singapore, the heart of Asia and a nodal point connecting 600 major ports, handles 80,000 containers (boxes) and 50 merchant ships per year via 200 shipping companies [1].

Container ship management is a very important subject in maritime logistics because of unforeseen expenditures and the waiting time at ports due to global economic conditions. In addition to these consequences, the coronavirus disease-2019 pandemic appears to have caused investors to be uncertain. Therefore, a container ship investor should conduct an investment analysis before investing in a container ship to avoid high costs. In the literature, these investment analyses have been studied in different forms [2-10].

Vagueness and indefiniteness play a significant role in investment analysis. Indefiniteness can be handled using fuzzy sets, which were proposed by Zadeh [11] in 1965. Since then, fuzzy logic and its extensions, such as fuzzy multisets, Fermatean fuzzy sets, hesitant fuzzy sets, Pythagorean fuzzy sets, picture fuzzy sets, and q-rung orthopair fuzzy sets, have been presented for addressing vagueness. Fuzzy set and its extensions generally use

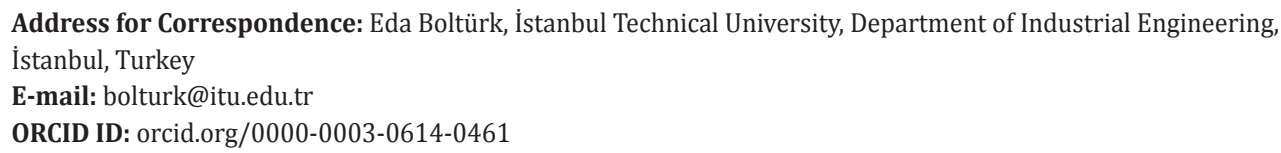

Received: 24.07 .2021 Accepted: 18.10 .2021

To cite this article: E. Boltürk, “Container Ship Investment Analysis Using Picture Fuzzy Present Worth Analysis.” Journal of ETA Maritime Science, vol. 9(4), pp. 233-242, 2021.

${ }^{\circ}$ Copyright 2021 by the Journal of ETA Maritime Science published by UCTEA Chamber of Marine Engineers 
membership function as a parameter for expressing human thoughts in modeling problems. These extensions are provided in Figure 1.

\begin{tabular}{|c|}
\hline Ordinary Fuzzy Sets [11] \\
\hline Type-2 Fuzzy Sets [12] \\
\hline 25 \\
\hline Interval-Valued Fuzzy Sets [13-15] \\
\hline $2 \sqrt{2}+\frac{1}{2}$ \\
\hline Intuitionistic Fuzzy Sets [16] \\
\hline Fuzzy Multicets [17] \\
\hline $2 \sqrt{2}$ \\
\hline Intuitionistic Fuzzy Sets of Second Type [18] \\
\hline 27 \\
\hline Neutrosophic Fuzzy Sets [19] \\
\hline 25 \\
\hline Nonstationary Fuzzy Sets [20] \\
\hline Hesitant Fuzzy Sets [21] \\
\hline 25 \\
\hline Pythagorean Fuzzy Sets [22] \\
\hline 25 \\
\hline Picture Fuzzy Sets [23] \\
\hline 52 \\
\hline q-rung Orthopair Fuzzy Sets [24] \\
\hline 28 \\
\hline Fermatean Fuzzy Sets [25] \\
\hline Spherical Fuzzy Sets [26] \\
\hline 28 \\
\hline Circular Intuitionistic Fuzzy Sets [27] \\
\hline
\end{tabular}

Figure 1. Milestones of fuzzy set extensions

Benefit/cost ratio analysis, rate of return analysis, annual cash flow analysis, payback period analysis, and present worth analysis are some of the mathematical methods used for investment analysis under engineering economics subjects. The present worth analysis consists of first cost (FC), interest rate (i), annual benefits (AB), life (n), annual cost (AC), and salvage value (SV) parameters. In the literature, the present worth analysis has been extended to its fuzzy extension forms. Kahraman et al. [28] introduced discounting technique-based financial models. Iliev and Fustik [29] presented fuzzy net present values for assessing hydroelectric projects. Omitaomu et al. [30] presented a present value model for information system projects using triangular fuzzy numbers. Kahraman et al. [31] introduced a fuzzy present worth analysis-based fuzzy model for quantifying manufacturing flexibility with triangular fuzzy numbers. Kahraman and Kaya [32] introduced an investment assessment using fuzzy equivalent annual worth (AW) analysis. Matos and Dimitrovski [33] presented a triangular fuzzy equivalent uniform AW analysis. Kuchta [34] used fuzzy present worth analysis for optimization. Dimitrovski and Matos [35] presented a fuzzy present worth analysis with uncorrelated and correlated cash flow. Shahriari [36] introduced the triangular fuzzy net present value methodology. Kahraman et al. [37] introduced two fuzzy present and AW analyses using intuitionistic and hesitant fuzzy sets with triangular fuzzy numbers. Sarı and Kahraman [38] presented type-2 net present worth analysis. Kahraman et al. [39] presented Pythagorean present worth analysis. Kahraman et al. [40] studied the present worth analysis in wind energy using ordinary fuzzy, type-2 fuzzy, hesitant fuzzy, and intuitionistic fuzzy present worth analyses. Aydin et al. [41] introduced a simplified neutrosophic present worth analysis method and compared it to intuitionistic and ordinary fuzzy present value analyses. Aydin and Kabak [42] developed neutrosophic future and present worth techniques. Sergi and Sari [43] introduced the Fermatean fuzzy capital budgeting method. Çevik Onar et al. [44] presented a spherical engineering economic analysis for evaluating solar energy investment. Bolturk and Seker [45] introduced the spherical fuzzy present worth analysis as a new fuzzy extension of the present worth analysis for analyzing an investment in a summer house in Istanbul.

A literature review was conducted in the Scopus database for fuzzy present worth analysis in order to observe the trend. Figure 2 illustrates the distribution of publications/papers on fuzzy present worth analysis by year, with most of the studies (15\%) published in 2018. Figure 3 shows the distribution of document types on fuzzy present worth analysis, with most of the papers (65\%) published as articles. Additionally, papers/ publications on fuzzy present worth analysis are handled as conference papers, book chapters, conference reviews, and reviews. Figure 4 shows the distribution of papers/ publications on fuzzy present worth analysis with respect to their source countries, with Turkey being the leading country. Figure 5 shows the percentage of the top 9 authors who published papers/publications on fuzzy present worth analysis, with Cengiz Kahraman being the leading author.

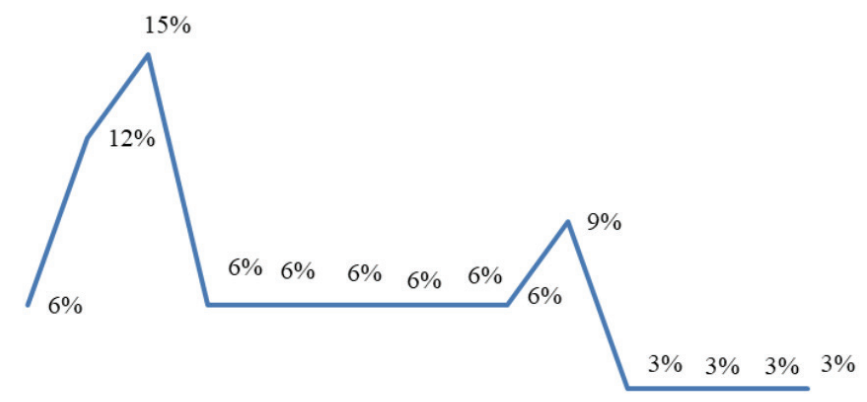

20212020201820172016201520142012201120082007200620042003

Figure 2. Distribution of papers/publications on fuzzy present worth analysis with respect to years 


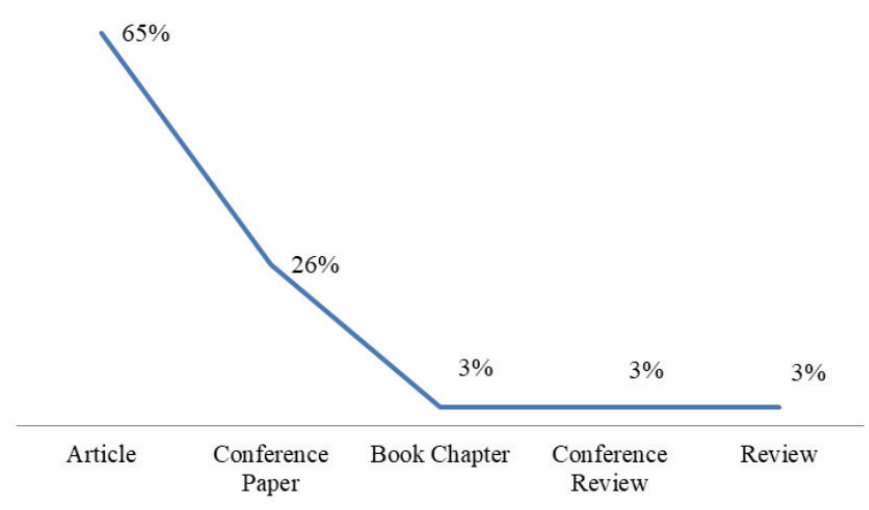

Figure 3. Distribution of papers/publications on fuzzy present worth analysis with respect to publication types

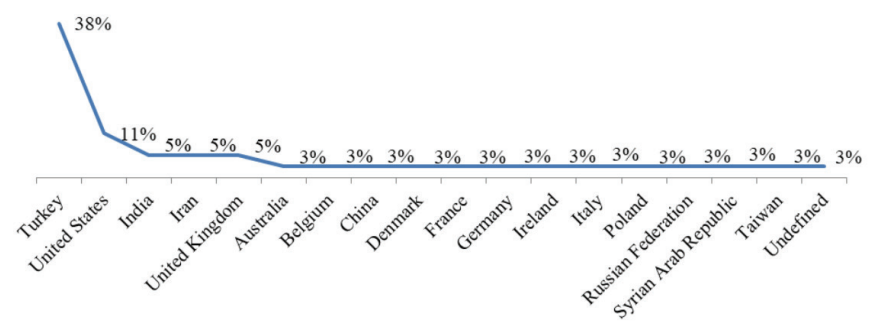

Figure 4. Distribution of papers/publications on fuzzy present worth analysis with respect to countries
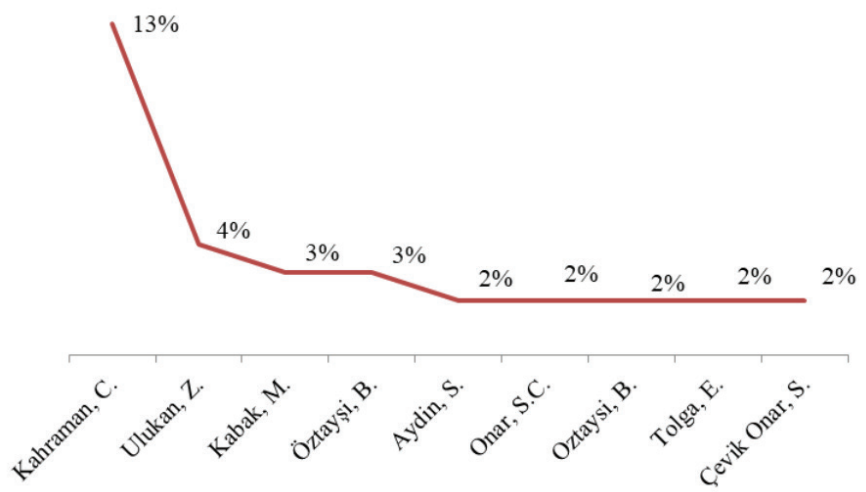

Figure 5. Percentages of the top 9 authors who published fuzzy present worth analysis papers/publications

Engineering, computer science, mathematics, economics, econometrics and finance, social sciences, decision sciences, business management and accounting, earth and planetary sciences, environmental science, energy, multidisciplinary, physics, and astronomy are the subject areas covered in papers/publications on the fuzzy present worth analysis. Furthermore, when publications/papers on fuzzy present worth analysis were investigated based on their sources, Advances in Intelligent Systems and Computing, The Engineering Economist, Fuzzy Sets and Systems, IEEE Transactions on Geoscience and Remote
Sensing, and Journal of Intelligent and Fuzzy Systems were seen as the first three sources. Kozan [46] combined capital budgeting techniques and queuing simulation models with a cost-benefit analysis to analyze an optimal balance between the opportunity cost of ship waiting time and the cost of expanding the seaport system. Koenig [47] introduced an option-based analysis and developed optioninformed naval analyses for real options in ships using force structure analysis. Rehder et al. [48] conducted a technoeconomic analysis and a risk analysis for sea transport, and the safety level of the new concept was compared to that of ship types. Marinacci et al. [49] used the cost-benefit analysis to evaluate voltage, power demand, frequency, and power supply parameters on the quay ships in cold-ironing scenarios. Pawlak [50] evaluated the economic benefits and environmental costs of marine vessel fuels from the perspectives of the infrastructure event. In 2015, Santos and Guedes Soares [51] evaluated the economic feasibility of a liquefied natural gas bunkering service in the Atlantic islands and Portuguese coast. Furtado et al. [52] used an input-output analysis to assess the economic and social impacts of local content management in oil and gas and shipbuilding industries in Brazil. Truszczyński and Pezała [53] identified and characterized container terminal congestion to develop a decision-making model in order to reduce the risk of congestion, which has negative economic, social, and environmental consequences. van der Kolk et al. [54] developed a vessel model for the performance of wind-assisted ships that was combined with a routing tool to evaluate the fuel savings available from the installation using a combination of economic analyses. The results of this case study are presented in terms of fuel savings and payback period analysis. Jiang et al. [55] analyzed economic investment, technical standards, management regulations, and other issues that arise during the actual promotion process, as well as conducted research on pure batterypowered ships for the Yangtze River.

To the best of our knowledge, there is no present worth analysis study that is based on picture fuzzy sets in engineering economics. The main goal of this study is to introduce picture fuzzy present worth analysis, a new method for present worth analysis with picture fuzzy sets. In this study, picture fuzzy present worth analysis is a novel proposed method that is used in the shipping industry. This paper is organized as follows: the preliminaries of picture fuzzy sets are presented as definitions and formulas in Section 2, the proposed picture fuzzy present worth analysis is presented step by step in Section 3, an application for calculating the present worth value of a container ship investment is provided in Section 4 to demonstrate the applicability of the proposed method, and 
future suggestions and obtained results are summarized in Section 5 as a conclusion.

\section{Picture Fuzzy Sets}

In 2014, Cuong and Kreinovich introduced picture fuzzy sets as a new fuzzy set extension [56]. Picture fuzzy setbased models, which are sufficient in situations where we encounter human ideas, include more types of responses, such as "yes," refusal, "abstain," and "no" [56]. A voting example can be used to illustrate in detail. Human voters can be divided into four groups: those who "vote for," "refuse to vote," "vote against," and are "hesitant" [56]. The following are the definitions of picture fuzzy sets:

Definition 1: A picture fuzzy set on an $\tilde{A}_{p}$ of the universe of discourse, $U$, is shown in Equations 1, 2:

$$
\tilde{A}_{p}=\left\{\left\langle u,\left(\mu_{\tilde{A}_{p}}(u), v_{\tilde{A}_{p}}(u), \pi_{\tilde{A}_{p}}(u)\right)\right| u \in U\right\},
$$

where

$\mu_{\tilde{A}_{p}}(u): U \rightarrow[0,1], v_{\tilde{A}_{p}}(u): U \rightarrow[0,1], \pi_{\tilde{A}_{p}}(u): U \rightarrow[0,1]$,

and

$$
0 \leq \mu_{\tilde{A}_{p}}(u)+v_{\tilde{A}_{p}}(u)+\pi_{\tilde{A}_{p}}(u) \leq 1 \quad \forall u \in U .
$$

Thus, for each $\boldsymbol{u}$, numbers $\mu_{\tilde{A}_{s}}(u), v_{\tilde{A}_{s}}(u)$, and $\pi_{\tilde{A}_{s}}(u)$ are the degrees of membership, non-membership, and hesitancy of $u$ to $\tilde{A}_{S}$, respectively. The formula of refusal degree is provided in Equation 3 for picture fuzzy sets [56].

$\rho=1-\left(\mu_{\tilde{A}_{p}}(u)+v_{\tilde{A}_{p}}(u)+\pi_{\tilde{A}_{p}}(u)\right)$

Definition 2: The basic operators for single-valued picture fuzzy sets are presented in Equations 4-7 [56].

$$
\begin{aligned}
& \tilde{A}_{p} \oplus \tilde{B}_{p}=\left\{\mu_{\tilde{A}_{p}}+\mu_{\tilde{B}_{p}}-\mu_{\tilde{A}_{p}} \mu_{\tilde{B}_{p}}, \pi_{\tilde{A}_{p}} \pi_{\tilde{B}_{p}}, v_{\tilde{A}_{p}} v_{\tilde{B}_{p}}\right\}, \\
& \tilde{A}_{p} \otimes \tilde{B}_{p}=\left\{\mu_{\tilde{A}_{p}} \mu_{\tilde{B}_{p}}, \pi_{\tilde{A}_{p}}+\pi_{\tilde{B}_{p}}-\pi_{\tilde{A}_{p}} \pi_{\tilde{B}_{p}}, v_{\tilde{A}_{p}}+v_{\tilde{B}_{p}}-v_{\tilde{A}_{p}} v_{\tilde{B}_{p}}\right\}, \\
& \lambda \cdot \tilde{A}_{p}=\left\{\left(1-\left(1-\mu_{\tilde{A}_{p}}\right)^{\lambda}\right), \pi_{\tilde{A}_{p}}^{\lambda}, v_{\tilde{A}_{p}}^{\lambda}\right\} \text { for } \lambda>0, \\
& \tilde{A}_{p}^{\lambda}=\left\{\mu_{\tilde{A}_{p}}^{\lambda},\left(1-\left(1-v_{\tilde{A}_{p}}\right)^{\lambda}\right),\left(1-\left(1-\pi_{\tilde{A}_{p}}\right)^{\lambda}\right)\right\} \text { for } \lambda>0 .
\end{aligned}
$$

Definition 3: Wei [57] proposed a single-valued picture fuzzy weighted averaging (PFWA) operator for picture fuzzy sets with respect to $w=\left(w_{1}, w_{2} \ldots \ldots, w_{n}\right) ; w_{i} \in[0,1]$; $\sum_{i=1}^{n} w_{i}=1$ is presented in Equation 8;

$$
\begin{aligned}
\operatorname{PFWA}_{w}\left(\tilde{A}_{1}, \ldots \ldots . ., \tilde{A}_{n}\right) & =w_{1} \tilde{A}_{1}+w_{2} \tilde{A}_{2}+\ldots \ldots+w_{n} \tilde{A}_{n} \\
& =\left\{1-\prod_{i=1}^{n}\left(1-\mu_{\tilde{A}_{i}}\right)^{w_{i}}, \prod_{i=1}^{n} v_{\tilde{A}_{i}}^{w_{i}}, \prod_{i=1}^{n} \pi_{\tilde{A}_{i}}^{w_{i}}\right\}
\end{aligned}
$$

Definition 4: [58] Equations 9 and 10 define the score and accuracy functions for sorting picture fuzzy numbers (PFNs), respectively. Equation 9 can also be used to defuzzify PFNs.

$$
\operatorname{Score}\left(\tilde{A}_{p}\right)=\frac{1}{2}\left(1+2 \mu_{\tilde{A}_{p}}-v_{\tilde{A}_{p}}-\pi_{\tilde{A}_{p}} / 2\right),
$$

$$
\operatorname{Accuracy}\left(\tilde{A}_{p}\right)=\mu_{\tilde{A}_{p}}+v_{\tilde{A}_{p}}+\pi_{\tilde{A}_{p}} .
$$

Note that $\tilde{A}_{p}<\tilde{B}_{p}$ if and only if

(i) Score $\left(\tilde{A}_{p}\right)<\operatorname{Score}\left(\tilde{B}_{p}\right)$ or

(ii) Score $\left(\tilde{A}_{p}\right)=\operatorname{Score}\left(\tilde{B}_{p}\right)$ and Accuracy $\left(\tilde{A}_{p}\right)<\operatorname{Accuracy}\left(\tilde{B}_{p}\right)$.

\section{Proposed Picture Fuzzy Present Worth Method}

Picture fuzzy sets are a direct extension of intuitionistic fuzzy sets that can model uncertainty in situations involving more of yes, abstain, and no answer types. The concept of neutrality degree can be observed in situations where we are confronted with human opinions involving more answer types, such as yes, abstain, no, and refusal [59]. Thus, picture fuzzy sets were chosen to extend the present worth analysis method. The difference between picture fuzzy sets and intuitionistic fuzzy sets is the concept of neutrality degree, which is missing from the intuitionistic fuzzy set theory [59].

The FC, SV, AB, AC, i, and $\mathrm{n}$ parameters are provided with picture fuzzy membership values and expressed as PFNs in Equations 11-16.

$$
\begin{aligned}
& \widetilde{F C}_{P}=\left\{\begin{array}{c}
\left\langle f c_{1}, N_{1}, \ldots, P F N_{m}\right\rangle,\left\langle f c_{2}, S P N_{1}, \ldots, P F N_{m}\right\rangle, \\
\ldots,\left\langle f c_{k}, P F N_{1}, \ldots, P F N_{m}\right\rangle
\end{array}\right\}, \\
& \widetilde{A C}_{P}=\left\{\begin{array}{c}
\left\langle a c_{1}, P F N_{1}, \ldots, P F N_{m}\right\rangle,\left\langle a c_{2}, P F N_{1}, \ldots, P F N_{m}\right\rangle, \ldots, \\
\left\langle a c_{k}, P F N_{1}, \ldots, P F N_{m}\right\rangle
\end{array}\right\}, \\
& \widetilde{A B}_{P}=\left\{\begin{array}{c}
\left\langle a b_{1}, P F N_{1}, \ldots, P F N_{m}\right\rangle,\left\langle a b_{2}, P F N_{1}, \ldots, P F N_{m}\right\rangle, \ldots, \\
\left\langle a b_{k}, P F N_{1}, \ldots, S P N_{m}\right\rangle
\end{array}\right\}, \\
& \widetilde{S V}_{P}=\left\{\begin{array}{c}
\left\langle s v_{1}, P F N_{1}, \ldots, P F N_{m}\right\rangle,\left\langle s v_{2}, P F N_{1}, \ldots, P F N_{m}\right\rangle, \ldots, \\
\left\langle s v_{k}, P F N_{1}, \ldots, P F N_{m}\right\rangle
\end{array}\right\},
\end{aligned}
$$




$$
\begin{aligned}
& \tilde{\iota}_{P}=\left\{\begin{array}{c}
\left\langle i_{1}, P F N_{1}, \ldots, P F N_{m}\right\rangle,\left\langle i_{2}, P F N_{1}, \ldots, P F N_{m}\right\rangle, \ldots, \\
\left\langle i_{k}, P F N_{1}, \ldots, P F N_{m}\right\rangle
\end{array}\right\}, \\
& \tilde{n}_{P}=\left\{\begin{array}{c}
\left\langle n_{1}, P F N_{1}, \ldots, P F N_{m}\right\rangle,\left\langle n_{2}, P F N_{1}, \ldots, P F N_{m}\right\rangle, \ldots, \\
\left\langle n_{k}, P F N_{1}, \ldots, P F N_{m}\right\rangle
\end{array}\right\},
\end{aligned}
$$

The present worth analysis value is calculated using Equation 17 as follows:

$$
\begin{aligned}
\widetilde{P W}_{P}= & -\widetilde{F C}_{P}-\widetilde{A C}_{P}\left[\frac{\left(1+\tilde{\imath}_{P}\right)^{\tilde{n}_{P}-1}}{\tilde{\imath}_{P}\left(1+\tilde{l}_{P}\right)^{\tilde{n}_{P}}}\right]+\widetilde{A B}_{P}\left[\frac{\left(1+\tilde{\imath}_{P}\right)^{\tilde{n}_{P}-1}}{\tilde{\imath}_{P}\left(1+\tilde{l}_{P}\right)^{\tilde{n}_{P}}}\right] \\
& +\widetilde{S V}_{P}\left(1+\tilde{\imath}_{P}\right)^{-\tilde{n}_{P}}
\end{aligned}
$$

where $\overparen{P W_{P}}$ is picture fuzzy present worth, $\overparen{F C_{P}}$ is picture fuzzy $F C, \widetilde{A B}_{P}$ is picture fuzzy $\mathrm{AB}, \widetilde{A C}_{P}$ is picture fuzzy $\mathrm{AC}, \boldsymbol{t}_{P}$ is picture fuzzy i, $\widetilde{S V}$ is picture fuzzy $S V$, and $\pi_{P}$ is picture fuzzy $n$.

Picture fuzzy set aggregation was executed using Equation 8. After aggregation, parameter values can be calculated by multiplying the defuzzified parameter values with membership functions. The score function and defuzzification of memberships are used to obtain crisp values for each parameter. Figure 6 shows the steps for the proposed picture fuzzy present worth analysis method as a flowchart.

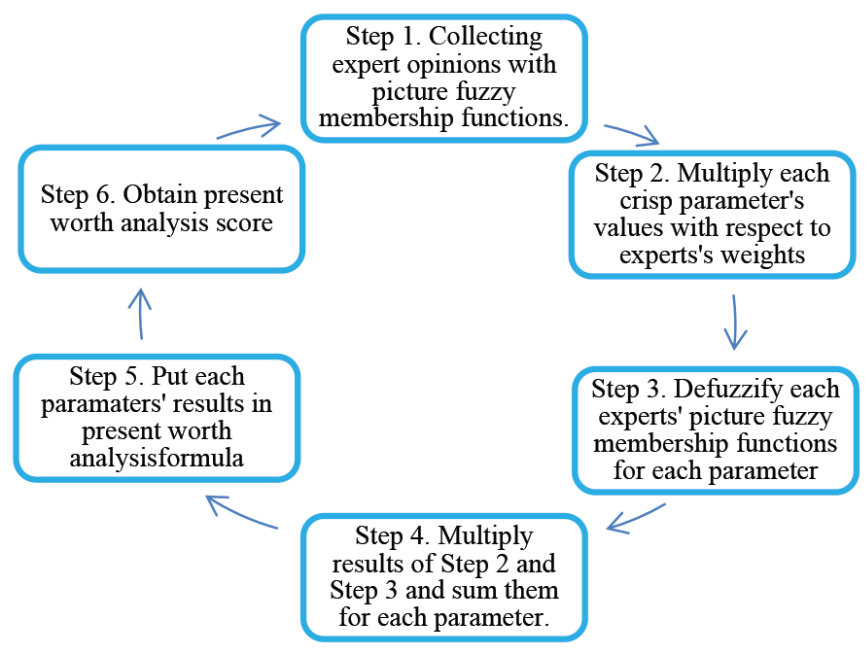

Figure 6. Flowchart of the proposed picture fuzzy present worth analysis method

\section{Application: Container Ship Investment Analysis}

An illustrative example is presented in this section. In this study, a generated unreal container ship, m/v EdBmU, was considered. The problem was constructed based on the information provided by five experts from the maritime logistics field. These experts are named E1, E2, E3, E4, and E5, and they each present their weighted opinions. The parameter values are provided approximately. Each expert was weighted based on their personal experiences, and E3 had the most weight because he has worked in the maritime logistics sector for a long time. The experts' weights are $0.1,0.2,0.3,0.15$, and 0.25 , respectively. Table 1 presents the experts' thoughts on EdBmU as values. Each parameter value in Table 1 consists of an unreal data set that converges to a real data set. Each expert assigned picture fuzzy set memberships independently, with picture fuzzy membership for each parameter. The limitation of this study is that the summation membership, non-membership, and hesitancy of picture fuzzy membership is between 0 and 1 .

AC includes annual maintenance cost, fuel, management cost, labor cost, and insurance cost, while AB includes trade profit.

The following is a list of detailed data regarding the present worth analysis of the container ship in this application:

- Ship Type Characteristics: A geared cargo-handling container ship.

- Capital Expenditures: The FC consists of purchasing cost, loan expenditures, credit installment, insurance cost, and container equipment.

- Operational Expenditure: The operational expenditures (AC) of the container ship are crew expenditures, victualing, maintenance and repair costs, spares, stores, lubricant, surveys and audits, dry dock costs, communication costs, administration costs, brokerage, and insurance. The depreciation costs, such as scrap metal prices and lightship displacement, are handled in this item.

- Revenue: The revenue is handled using the AB and SV parameters. The revenue of this container ship is derived from annual freight and SV at the end of its service life.

Table 2 shows the weighted values and defuzzified membership functions. Equation (9) is used to defuzzify these membership functions. The defuzzified membership function for E1's thoughts on FC is calculated as follows (Equation 18):

$$
F C_{E 1}=\frac{1}{2} \times\left(1+2 \times 0.5-0.4-\frac{0.1}{2}\right)=0.775 \text {, }
$$

Table 3 shows the score values calculated using Table 2 values and Equation 8.

The total defuzzified score for;

$$
\begin{aligned}
n= & 3 \times 0.425+6.4 \times 1.100+9.9 \times 1.025 \\
& +4.65 \times 0.475+8.75 \times 0.875=28.328 .
\end{aligned}
$$

To obtain the present worth analysis values, the score values are entered into the present worth formula. For the $\mathrm{m} / \mathrm{v}$ EdBmU container ship, the score value is $\$ 896,887.85$. 


$$
\begin{aligned}
P W A_{E d B m U}= & -1448125+1032312.5 \times\left(\frac{(1+0.44)^{28.328}-1}{0.44 \times(1+0.44)^{28.328}}\right) \\
& -620.313 \times\left(\frac{(1+0.44)^{28.328}-1}{0.44 \times(1+0.44)^{28.328}}\right) \\
& +44217.50 \times(1+0.44)^{-28.328}, \\
P W A_{E d B m U}= & \$ 896,887.85 .
\end{aligned}
$$

\section{Sensitivity Analysis}

Sensitivity analysis is based on the total defuzzified scores, which are shown in Table 2 . The five experts mutually agreed that the most critical parameters in the present worth analysis are $F C$ and $A B$ because of unforeseen insurance costs and currency arbitrage. The AW formula is provided in Equation 21, and the sensitivity analysis parameters are obtained using Equation 21.

$$
\begin{aligned}
A W= & -F C(A / P, i \%, n)(1+x)+A B(1+y) \\
& -A C+S V(A / F, i \%, n), \\
A W= & -1448125(A / P, 4,4 \%, 28.32)(1+x) \\
& +103312.5(1+y)-620.313 \\
& +44217.5(A / F, 4,4 \%, 28.32),
\end{aligned}
$$

\begin{tabular}{|c|c|c|c|c|c|}
\hline Parameters & Experts & $\begin{array}{l}\text { Experts' } \\
\text { weights }\end{array}$ & $\begin{array}{l}\text { Picture fuzzy memberships } \\
\qquad(\mu, \vartheta, \pi)\end{array}$ & $\begin{array}{c}\text { Parameter values } \\
\text { (\$) }\end{array}$ & Picture fuzzy values \\
\hline \multirow{3}{*}{ First cost } & E1 & 0.1 & $(0.5,0.4,0.1)$ & $1,500,000$ & $\langle 1,500,000 ; 0.5,0.4,0.1\rangle$ \\
\hline & E3 & 0.3 & $(0.3,0.3,0.4)$ & $1,700,000$ & $\langle 1,700,000 ; 0.3,0.3,0.4\rangle$ \\
\hline & $\mathrm{E} 4$ & 0.15 & $(0.2,0.3,0.5)$ & $1,800,000$ & $\langle 1,800,000 ; 0.2,0.3,0.5\rangle$ \\
\hline \multirow{4}{*}{ Annual benefit } & E2 & 0.2 & $(0.6,0.1,0.1)$ & $1,750,000$ & $\langle 1,750,000 ; 0.6,0.1,0.1\rangle$ \\
\hline & E3 & 0.3 & $(0.1,0.2,0.3)$ & $1,800,000$ & $\langle 1,800,000 ; 0.1,0.2,0.3\rangle$ \\
\hline & $\mathrm{E} 4$ & 0.15 & $(0.1,0.3,0.3)$ & $1,750,000$ & $\langle 1,750,000 ; 0.1,0.3,0.3\rangle$ \\
\hline & E5 & 0.25 & $(0.2,0.3,0.5)$ & $1,700,000$ & $\langle 1,700,000 ; 0.2,0.3,0.5\rangle$ \\
\hline \multirow{2}{*}{ Annual cost } & E4 & 0.15 & $(0.4,0.5,0.1)$ & 650 & $\langle 650 ; 0.4,0.5,0.1\rangle$ \\
\hline & E5 & 0.25 & $(0.6,0.2,0.2)$ & 850 & $\langle 850 ; 0.6,0.2,0.2\rangle$ \\
\hline \multirow{5}{*}{ Salvage value } & E1 & 0.1 & $(0.8,0.1,0.1)$ & 65,000 & $\langle 65,000 ; 0.8,0.1,0.1\rangle$ \\
\hline & $\mathrm{E} 2$ & 0.2 & $(0.2,0.3,0.4)$ & 60,000 & $\langle 60,000 ; 0.2,0.3,0.4\rangle$ \\
\hline & E3 & 0.3 & $(0.6,0.1,0.1)$ & 55,000 & $\langle 55,000 ; 0.6,0.1,0.1\rangle$ \\
\hline & E4 & 0.15 & $(0.5,0.3,0.2)$ & 61,500 & $\langle 61,500 ; 0.5,0.3,0.2\rangle$ \\
\hline & E5 & 0.25 & $(0.1,0.3,0.3)$ & 70,000 & $\langle 70,000 ; 0.1,0.3,0.3\rangle$ \\
\hline Interest rate (i) & E1 & 0.1 & $(0.1,0.1,0.3)$ & 0.8 & $\langle 0.8 ; 0.1,0.1,0.3\rangle$ \\
\hline \multirow{3}{*}{ Life (n) } & E3 & 0.3 & $(0.6,0.1,0.1)$ & 33 & $\langle 33 ; 0.6,0.1,0.1\rangle$ \\
\hline & $\mathrm{E} 4$ & 0.15 & $(0.1,0.1,0.3)$ & 31 & $\langle 31 ; 0.1,0.1,0.3\rangle$ \\
\hline & E5 & 0.25 & $(0.5,0.2,0.1)$ & 35 & $\langle 35,0.5,0.2,0.1\rangle$ \\
\hline
\end{tabular}

$$
\begin{aligned}
A W= & -1448125 \times\left(\frac{\left.(1+0.044)^{28.32}-1\right)}{0.044 \times(1+0.044)^{28.32}}\right)^{-1}(1+x) \\
& +103312.5(1+y)-620.313 \\
& +44217.5 \times\left(\frac{(1+0.044)^{28.32}-1}{0.044}\right)^{-1},
\end{aligned}
$$

Table 1. The values for the $m / v$ EdBmU container ship 


$$
\begin{aligned}
&=-63719.59-63719.59 x+103312.5+103312.5 y \\
&-620.313+815.65 \\
&=-63719.59 x+103312.5 y+970028.87 \\
&(x, y)=(15.22 ; 0) \\
&(x, y)=(0 ;-0.94)
\end{aligned}
$$

\begin{tabular}{|c|c|c|c|}
\hline Parameters & Experts & Weighted values & $\begin{array}{c}\text { Defuzzified } \\
\text { membership } \\
\text { functions }\end{array}$ \\
\hline \multirow{5}{*}{ First cost } & E1 & 150,000 & 0.775 \\
\hline & E2 & 440,000 & 1.025 \\
\hline & E3 & 510,000 & 0.550 \\
\hline & E4 & 270,000 & 0.425 \\
\hline & E5 & 525,000 & 0.925 \\
\hline \multirow{5}{*}{ Annual benefit } & E1 & 150,000 & 1.100 \\
\hline & E2 & 350,000 & 1.025 \\
\hline & E3 & 540,000 & 0.425 \\
\hline & E4 & 262,500 & 0.375 \\
\hline & E5 & 425,000 & 0.425 \\
\hline \multirow{5}{*}{ Annual cost } & E1 & 80 & 0.700 \\
\hline & E2 & 180 & 0.425 \\
\hline & E3 & 225 & 1.000 \\
\hline & E4 & 97.5 & 0.625 \\
\hline & E5 & 212.5 & 0.950 \\
\hline \multirow{5}{*}{ Salvage value } & E1 & 6,500 & 1.225 \\
\hline & E2 & 12,000 & 0.450 \\
\hline & E3 & 16,500 & 1.025 \\
\hline & E4 & 9,225 & 0.800 \\
\hline & E5 & 17,500 & 0.375 \\
\hline \multirow{5}{*}{ Interest rate } & E1 & 0.08 & 0.475 \\
\hline & E2 & 0.18 & 1.025 \\
\hline & E3 & 0.17 & 0.425 \\
\hline & E4 & 0.12 & 0.475 \\
\hline & E5 & 0.21 & 0.425 \\
\hline \multirow{5}{*}{ Life } & E1 & 3.00 & 0.425 \\
\hline & E2 & 6.40 & 1.100 \\
\hline & E3 & 9.90 & 1.025 \\
\hline & $\mathrm{E} 4$ & 4.65 & 0.475 \\
\hline & E5 & 8.75 & 0.875 \\
\hline
\end{tabular}

Table 2. The values for the $m / v$ EdBmU container ship

Table 3. The scores of the present worth analysis parameters

\begin{tabular}{|c|c|c|}
\hline Parameters & Weighted values & Defuzzified total scores \\
\hline First cost & $1,895,000$ & $1,448,125$ \\
\hline Annual benefit & $1,727,500$ & $1,032,312.50$ \\
\hline Annual cost & 795 & 620.313 \\
\hline Salvage value & 61,725 & $44,217.500$ \\
\hline Interest rate & 0.76 & 0.440 \\
\hline Life & 32.70 & 28.328 \\
\hline
\end{tabular}

Figure 7 shows that the container ship investor incurs no risk if the $F C$ and $A B$ values are greater than the square of $\pm 51.43 \%$. This means that the container will remain unaffected by various changes in FC and AB up to $51.43 \%$ in any direction.

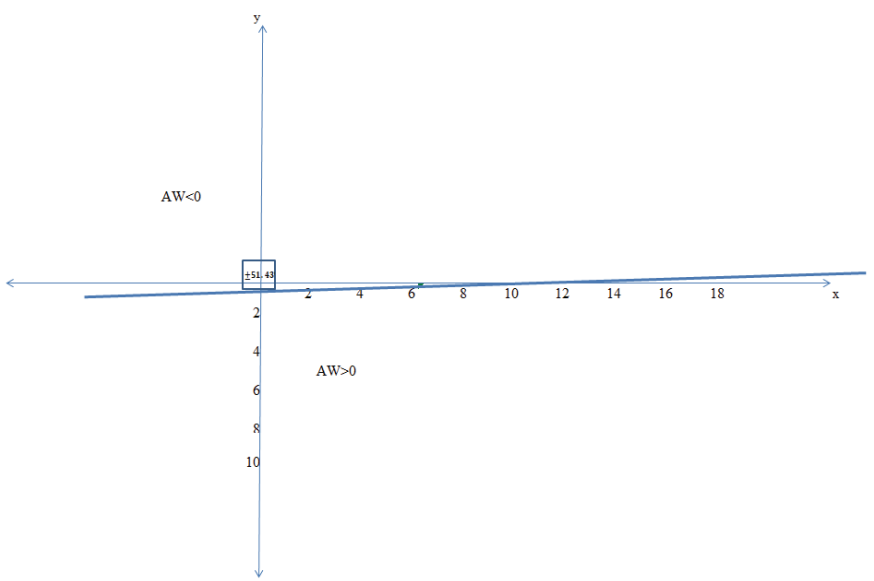

Figure 7. Sensitivity analysis of the $F C$ and $A B$ parameters

FC: First cost, AB: Annual benefits

\section{Comparison Analysis with Spherical Fuzzy Present Worth Analysis}

In this study, the proposed method was compared with the spherical fuzzy present worth analysis method, which was introduced by Bolturk and Seker [45], and all membership values were taken as spherical fuzzy numbers, as shown in Table 1. Score values were entered into the present worth formula to obtain the spherical fuzzy present worth analysis values, and the value for $\mathrm{m} / \mathrm{v} \mathrm{EdBmU}$ container ship is $\$ 471,022.809$. In addition, all parameters were aggregated using classic crisp arithmetic operations and the value for the $\mathrm{m} / \mathrm{v}$ EdBmU container ship is $\$ 424,475.86$ (Equations 28 and 29 as below).

$$
\begin{aligned}
\text { Spherical_PWA } A_{E d B m U}= & -1968268.03+1681001.73 \\
& \times\left(\frac{(1+0.70)^{32.77}-1}{0.70 \times(1+0.70)^{32.77}}\right) \\
& -787.26 \times\left(\frac{(1+0.70)^{32.77}-1}{0.70 \times(1+0.70)^{32.77}}\right) \\
& +60358.13 \times(1+0.70)^{-32.77},
\end{aligned}
$$

Spherical_PWA $A_{E d B m U}=\$ 471,022.81$

$$
\begin{aligned}
\text { Classic crisp_PWA } A_{E d B m U}= & -1895000+1727500 \\
& \times\left(\frac{(1+0.76)^{32.7}-1}{0.76 \times(1+0.76)^{32.7}}\right) \\
& -795 \times\left(\frac{(1+0.76)^{32.7}-1}{0.76 \times(1+0.76)^{32.7}}\right) \\
& +61725 \times(1+0.76)^{-32.7},
\end{aligned}
$$

Classic Crisp_PWA $A_{E d B m U}=\$ 424,475.86$ 


\section{Conclusion and Future Works}

Herein, a new fuzzy engineering economics analysis method called the picture fuzzy present worth analysis method is proposed, with an application for container ship investment analysis. Picture fuzzy set [57] is a recently used fuzzy set extension that uses positive membership, degree of membership, neutral membership, and degree of negative membership functions to handle vagueness. Human thoughts can be shaped with picture fuzzy sets when they consist of "yes," refusal, "abstain," and "no" answers [57].

Present worth analysis with fuzzy sets is widely used in investment analysis to better model the problem. In this study, the advantage of shaping human thoughts into four terms is used for investment analysis, and picture fuzzy sets were used in the present worth analysis. The proposed method was applied in an illustrative application. A container ship investment analysis was taken as a problem, and the parameter values of the present worth analysis were determined by five experts who work in the maritime logistics field. The picture fuzzy set parameters could model each expert's thoughts with degrees of positive membership, negative membership, and refusal membership. The experts' opinions were defuzzified based on picture fuzzy set definitions, and the defuzzified values were used in calculating the present worth. The present worth value in our application is $\$ 896,887.85$. Furthermore, the proposed method is compared with the spherical fuzzy present worth analysis method and classic crisp methods to demonstrate the applicability of the proposed method.

In future research, a comparison of the proposed picture fuzzy present worth analysis and other present worth analysis fuzzy extensions can be explored using different applications to understand the power of fuzzy set extensions. Additionally, new fuzzy set extensions, such as q-rung fuzzy sets, can be used in present worth analysis methods, and experts' opinions can be used to compare extended fuzzy present worth analysis methods with possible q-rung fuzzy orthopair present woth analysis. However, a holistic approach that considers the ship as a whole and includes the machinery can be examined in more detail.

Funding: The author declared that this study received no financial support.

\section{References}

[1] M. S. Bilican, 2021 "A mathematical model and two-stage heuristic for the container stowage planning problem with stability parameters," IEEE Access, vol. 8, pp. 113392-113413 Jun 2020.
[2] A. Abdullah, R Hassan, and S. Kassim, "A real asset managementapproach for islamic investment in containerships," Journal of Islamic Accounting and Business Research, vol. 11, pp. 27-48, Jan 2020.

[3] J. Jeevan, M. Menhat, and D. Anuar, "An empirical analysis on container vessels enlargement: exploring causal factors from the perspective of malaysian maritime trade system." International Journal of Recent Technology and Engineering, vol. 8, pp. 366373, May 2019.

[4] I. Dimakopoulos, P. Menegakis, N. Lampris, S. Gkinis, and Panagoulias, G. Replacement of a diesel generator with a containerised battery system on-board a containership. Paper presented at the RINA, Royal Institution of Naval Architects Power and Propulsion Alternatives for Ships, 2017.

[5] I. Kurt, E. Boulougouris, and O. Turan, "Cost based analysis of the offshore port system," Paper presented at the Proceedings of the International Conference on Offshore Mechanics and Arctic Engineering - OMAE, Oct 2015

[6] I. C. Stefanatos, G. G. Dimopoulos, and N. M. P. Kakalis, Modelbased performance assessment and optimisation of waste heat recovery systems for containerships. Paper presented at the RINA, Royal Institution of Naval Architects - Design and Operation of Container Ships, Papers, 97-105, 2014.

[7] S. Yu, J. Chen, and S. Huang, "Ship investment timing based on option to defer with mean reversion motion," Tongji Daxue Xuebao/Journal of Tongji University, vol. 42, pp. 1931-1934, Dec 2014.

[8] H. R. Choi, B. J. Park, D. H. Yoo, M. H. Kang and S. J. Yoon. "Development of a model based on system dynamics to strengthen the competitiveness of a container terminal," WSEAS Transactions on Information Science and Applications, vol. 4, 988-995, May 2007.

[9] A. J. Baird, "Containerization and the decline of the upstream urban port in europe," Maritime Policy and Management, vol. 23, 145-156, 1996.

[10] I. Kurt, E. Boulougouris, and O. Turan, "Cost based analysis of the offshore port system," Paper presented at the Proceedings of the International Conference on Offshore Mechanics and Arctic Engineering - OMAE, 2015.

[11] L. A. Zadeh, “Fuzzy sets," Information Control, vol. 8, pp. 338-353, Jun 1965.

[12] L. A. Zadeh, "The concept of a linguistic variable and its application to approximate reasoning," Information Sciences, vol. 8, 199-249, 1975.

[13] I. Grattan-Guiness, "Fuzzy membership mapped onto interval and many-valued quantities." Z. Math. Logik. Grundladen Math. vol. 22, pp. 149-160, 1976.

[14] R. Sambuc, "Fonctions $\varphi$-floues. Application l'aide au diagnostic en pathologie thyroidienne," $\mathrm{Ph}$. D. Thesis, University of Marseille, France, 1975.

[15] K. U. Jahn, Intervall-wertige Mengen, Mathematische Nachrichten, vol. 68, pp. 115-132, 1975.

[16] K. Atanassov, "Intuitionistic fuzzy sets." Fuzzy Sets and Systems vol. 20, pp. 87-96, Aug 1986.

[17] R. R. Yager, "On the theory of bags." International Journal of General System, vol. 13, pp. 23-37, 1986. 
[18] K. T. Atanassov, "More on intuitionistic fuzzy sets," Fuzzy Sets and Systems, vol. 33, pp. 37-45, Oct 1989.

[19] F. Smarandache, A Unifying Field in Logics: Neutrosophic Logic. Neutrosophy, Neutrosophic Set, Neutrosophic Probability and Statistics, Infinite Study, 2003.

[20] J. M. Garibaldi and T. Ozen, "Uncertain fuzzy reasoning: A case study in modelling expert decision making." IEEE Transactions on Fuzzy Systems, vol. 15, pp. 16-30, Feb 2007.

[21] V. Torra, "Hesitant fuzzy sets," International Journal of Intelligent Systems, vol. 25, pp. 529-539, Mar 2010.

[22] R. R. Yager, A. M. Abbasov, "Pythagorean membership grades, complex numbers, and decision making”, International Journal of Intelligent Systems, vol. 28, pp. 436-452, Mar 2013.

[23] B. C. Cường, “Picture fuzzy sets," Journal of Computer Science and Cybernetics, vol. 30, pp. 409, Dec 2014.

[24] R. R. Yager, Generalized orthopair fuzzy sets. IEEE Transactions on Fuzzy Systems, vol. 25, pp. 1222-1230, Aug 2016.

[25] T. Senapati and R. R. Yager, "Fermatean fuzzy sets," Journal of Ambient Intelligence and Humanized Computing, vol. 11, pp. 663674, Feb 2020.

[26] F. Kutlu Gündoğdu and C. Kahraman, "Spherical fuzzy sets and spherical fuzzy topsis method." Journal of Intelligent \& Fuzzy Systems, vol. 36, pp. 337-352, Feb 2019.

[27] K. T. Atanassov, "Circular intuitionistic fuzzy sets." Journal of Intelligent \& Fuzzy Systems, vol. 39, pp. 5981-5986, Nov 2020.

[28] C. Kahraman, E. Tolga and Z. Ulukan, "Fuzzy flexibility analysis in automated manufacturing systems," Proceedings 1995 INRIA/IEEE Symposium on Emerging Technologies and Factory Automation. ETFA'95, vol. 3, pp. 299-307, Oct 1995.

[29] A. Iliev, V. Fustik, "Fuzzy logic approach for hydroelectric project evaluation," Paper presented at the IFAC Proceedings Volumes (IFAC-PapersOnline), vol. 36, pp. 241-246, Jun 2003.

[30] H. O. Omitaomu, C. G. Nsofor, and A. B. Badiru, "Integrative present value analysis model for evaluating information system projects," Paper presented at the IIE Annual Conference. Proceedings. Institute of Industrial and Systems Engineers (IISE), pp. 2065-2070, May 2004.

[31] C. Kahraman, A. Beskese and D. Ruan, "Measuring flexibility of computer integrated manufacturing systems using fuzzy cash flow analysis," Information Sciences, vol. 168, pp. 77-94, Dec 2004.

[32] C. Kahraman and I. Kaya, "Fuzzy equivalent annual-worth analysis and applications" In: Kahraman C. (eds) Fuzzy Engineering Economics with Applications. Studies in Fuzziness and Soft Computing, vol 233. Springer, Berlin, Heidelberg. 2008.

[33] M. Matos, A. Dimitrovski "Case studies using fuzzy equivalent annual worth analysis," In: Kahraman C. (eds) Fuzzy Engineering Economics with Applications. Studies in Fuzziness and Soft Computing, vol 233. Springer, Berlin, Heidelberg, pp. 83-95, 2008.

[34] D. Kuchta, "Optimization with fuzzy present worth analysis and applications," In: Kahraman C. (eds) Fuzzy Engineering Economics with Applications. Studies in Fuzziness and Soft Computing, vol 233. Springer, Berlin, Heidelberg.

[35] A. Dimitrovski and M. Matos, "Fuzzy present worth analysis with correlated and uncorrelated cash flows," In: Kahraman C. (eds) Fuzzy Engineering Economics with Applications. Studies in Fuzziness and Soft Computing, vol 233. Springer, Berlin, Heidelberg, 2008.

[36] M. Shahriari, "Mapping fuzzy approach in engineering economics," International Research Journal of Finance and Economics, vol. 81, pp. 6-12, 2011

[37] C. Kahraman, S. Çevik Onar and B. Öztayşi, "Engineering economic analyses using intuitionistic and hesitant fuzzy sets," Journal of Intelligent and Fuzzy Systems, vol. 29, pp. 1151-1168, Jan 2015.

[38] İ. U. Sarı and C. Kahraman, "Economic analysis of municipal solid waste collection systems using type-2 fuzzy net present worth analysis," In Intelligence Systems in Environmental Management: Theory and Applications, pp. 347-364, Jan 2017.

[39] C. Kahraman, S. Çevik Onar, B. Oztaysi, "Present worth analysis using pythagorean fuzzy sets," in Advances in Fuzzy Logic and Technology 2017. EUSFLAT 2017, IWIFSGN 2017. Advances in Intelligent Systems and Computing, J. Kacprzyk, E. Szmidt, S. Zadrożny, K. Atanassov, and M. Krawczak, Eds. vol. 642. New York: Springer, Cham, 2018.

[40] C. Kahraman, S. Çevik Onar, B. Öztayşi, İ. U. Sarı and E. İlbahar, "Wind energy investment analyses based on fuzzy sets," Energy Management-collective and Computational Intelligence with Theory and Applications, vol. 149, pp. 141-166, 2018.

[41] S. Aydin, C. Kahraman and M. Kabak, "Evaluation of investment alternatives using present value analysis with simplified neutrosophic sets," Engineering Economics, vol. 29, pp. 254-263, Jun 2018.

[42] S. Aydin and M. Kabak, "Investment analysis using neutrosophic present and future worth techniques," Journal of Intelligent and Fuzzy Systems, vol. 38, pp. 627-637, 2020.

[43] D. Sergi and I. U. Sari, "Fuzzy capital budgeting using fermatean fuzzy sets," 2021.

[44] S. Çevik Onar, B. Öztayși, C. Kahraman and İ. Otay, "Engineering economic analysis of solar energy investments using spherical fuzzy sets," World Scientific Proceedings Series on Computer Engineering and Information Science Developments of Artificial Intelligence Technologies in Computation and Robotics, pp. 182189,2020

[45] E. Bolturk, S. Seker, "Present Worth Analysis Using Spherical Fuzzy Sets," In: C. Kahraman, S. Cebi, S. Cevik Onar, B. Oztaysi, A.C. Tolga, I.U. Sari (eds) Intelligent and Fuzzy Techniques for Emerging Conditions and Digital Transformation. INFUS 2021. Lecture Notes in Networks and Systems, vol 308. Springer, Cham. 777-788, 2022.

[46] E. Kozan, "Optimal investment decisions for seaport systems." Paper presented at the National Conference Publication Institution of Engineers, Australia, pp. 239-243, 1992.

[47] P. C. Koenig, "Real options in ship and force structure analysis: A research agenda." Naval Engineers Journal, vol. 121, pp. 95-105, Oct 2009.

[48] G. Rehder, et al. "Methane hydrate pellet transport using the selfpreservation effect: A techno-economic analysis." Energies, vol. 5, pp. 2499-2523, Jul 2012.

[49] C. Marinacci, R. Masala, S. Ricci and A.Tieri, "Technicaleconomical analysis of cold-ironing: Case study of venice cruise terminal." 
Paper presented at the Computational Methods in Marine Engineering V - Proceedings of the 5th International Conference on Computational Methods in Marine Engineering, MARINE, 2013, pp. 564-574, 2013.

[50] M. Pawlak, "Analysis of economic costs and environmental benefits of LNG as the marine vessel fuel" 2015.

[51] T. A. Santos, and C. Guedes Soares, "Economic assessment of LNG bunkering in the Portuguese coast." Paper presented at the Towards Green Marine Technology and Transport - Proceedings of the 16th International Congress of the International Maritime Association of the Mediterranean, IMAM 2015, 695-704.

[52] S. R. Furtado, E. D. Júnior, M. F. L. Almeida, "Evaluation of social and economic impacts of local content management in oil \& gas and shipbuilding industry in Brazil: An application of inputoutput analysis." Paper presented at the OTC Brasil 2017, pp. 229-256, 2017.

[53] M. Truszczyński, A. Pezała, "Development investments at container terminals in the case of cargo congestion." Paper presented at the Safety of Sea Transportation - Proceedings of the International Conference on Marine Navigation and Safety of Sea Transportation, TRANSNAV 2017, 255-262. doi:10.1201/9781315099088-44, 2017.

[54] N. J. van der Kolk, G. Bordogna, J. C. Mason, P. Desprairies and A. Vrijdag, “Case study: Wind-assisted ship propulsion performance prediction, routing, and economic modelling." Paper presented at the RINA, Royal Institution of Naval Architects - Power and Propulsion Alternatives for Ships 2019.

[55] L. Jiang, Y. Ji, Y. Yi, K. Li "Research on the application of new energy pure battery powered ships in the yangtze river." Paper presented at the IOP Conference Series: Materials Science and Engineering, vol. 688, Dec 2019.

[56] B. C. Cuong and V. Kreinovich, "Picture Fuzzy Sets-a new concept for computational intelligence problems," In 2013 Third World Congress on Information and Communication Technologies (WICT 2013) pp. 1-6. IEEE. Dec 2013

[57] G. Wei, "Picture fuzzy aggregation operators and their application to multiple attribute decision making," Journal of Intelligent \& Fuzzy Systems, vol. 33, pp. 713-724, Jul 2017.

[58] G. Wei, "Picture fuzzy Hamacher aggregation operators and their application to multiple attribute decision making," Fundamenta Informaticae, vol. 157, pp. 271-320, Jan 2018.

[59] P. Dutta and S. Ganju, "Some aspects of picture fuzzy set," Transactions of A. Razmadze Mathematical Institute, vol. 172, pp. 164-175, Aug 2018. 